\title{
Changing global cropping patterns to minimize national blue water scarcity
}

\author{
Hatem Chouchane ${ }^{1}$, Maarten S. Krol ${ }^{1}$, and Arjen Y. Hoekstra ${ }^{1,2, t}$ \\ ${ }^{1}$ Twente Water Centre, University of Twente, Enschede, the Netherlands \\ ${ }^{2}$ Institute of Water Policy, Lee Kuan Yew School of Public Policy, National University of Singapore, Singapore \\ $\boldsymbol{t}_{\text {deceased, } 18 \text { November } 2019}$
}

Correspondence: Hatem Chouchane (hatemchouchane1@gmail.com)

Received: 4 September 2019 - Discussion started: 28 October 2019

Revised: 16 April 2020 - Accepted: 10 May 2020 - Published: 9 June 2020

\begin{abstract}
Feeding a growing population with global naturalresource constraints becomes an increasingly challenging task. Changing spatial cropping patterns could contribute to sustaining crop production and mitigating water scarcity. Previous studies on water saving through international food trade focussed either on comparing water productivities among food-trading countries or on analysing food trade in relation to national water endowments. Here, we consider, for the first time, how both differences in national average water productivities and water endowments can be considered to analyse comparative advantages of countries for different types of crop production. A linear-optimization algorithm is used to find modifications in global cropping patterns that reduce national blue water scarcity in the world's most severely water-scarce countries, while keeping global production of each crop unchanged and preventing any increase in total irrigated or rainfed harvested areas in each country. The results are used to assess national comparative advantages and disadvantages for different crops. Even when allowing a maximum expansion of the irrigated or rainfed harvested area per crop per country of only $10 \%$, the blue water scarcity in the world's most water-scarce countries can be greatly reduced. In this case, we could achieve a reduction of the global blue water footprint of crop production of $21 \%$ and a decrease of the global total harvested and irrigated areas of $2 \%$ and $10 \%$ respectively. Shifts in rainfed areas have a dominant share in reducing the blue water footprint of crop production.
\end{abstract}

\section{Introduction}

Water scarcity poses a major societal and economic risk (WEF, 2019) and threat to biodiversity and environmental sustainability (Vörösmarty et al., 2010). Population growth and climate change are expected to worsen the situation and impose more pressure on freshwater resources everywhere (Vörösmarty et al., 2000; Parry et al., 2004). Since water consumption already exceeds the maximum sustainable level in many parts of the world (Hoekstra et al., 2012) and population growth in water-scarce countries alone could enforce global international trade in staple crops to increase by a factor of 1.4 to 18 by 2050 (Chouchane et al., 2018), solutions are urgently needed for a more sustainable allocation of the world's limited freshwater resources (Hoekstra, 2014; Konar et al., 2016).

Considerable debate has arisen over the last few decades on the pathways to overcome the problem of water scarcity and its implications (Gleick, 2003), especially for agriculture, the largest consumer of freshwater, accounting for $92 \%$ of water consumption globally (Hoekstra and Mekonnen, 2012). A growing number of studies addresses the question of how to mitigate problems related to blue water scarcity (Wada et al., 2014; Kummu et al., 2016). Some proposed solutions focus on better water management in agriculture (Evans and Sadler, 2008), for instance, by improving irrigation efficiency and precision irrigation (Sadler et al., 2005; Greenwood et al., 2010), using better agricultural practices like mulching and drip irrigation (Mukherjee et al., 2010; Chukalla et al., 2015; Nouri et al., 2019), improving irrigation scheduling (Jones, 2004) and enhancing water pro- 
ductivity (Bouman, 2007; Molden et al., 2010; Pereira et al., 2012). Other suggested solutions focus on changing diets (Vanham et al., 2013; Jalava et al., 2014; Gephart et al., 2016) and reducing food losses (Munesue et al., 2015; Jalava et al., 2016) to diminish water consumption. Yet another category of studies focusses on spatial cropping patterns (Davis et al., 2017a, b) and the role of international trade in saving water and in bridging the gap between national water demand and supply in water-short countries (Chapagain et al., 2006; Hoekstra and Hung, 2005). The volume of fresh water used to produce a traded product, measured at the place where it was produced, also known as virtual water trade, is the hidden flow of water if food or other commodities are traded from one place to another (Allan, 1998). According to international trade theory, countries can profit from trade by focussing on the production and export of goods for which they have a comparative advantage. What precisely constitutes a comparative advantage is still subject to debate. Whereas Ricardo's theory of comparative advantage says that a country can best focus on producing goods for which they have relatively high productivity, the Heckscher-Ohlin $(\mathrm{H}-\mathrm{O})$ theory states that a country can best specialize in producing and exporting products that use production factors that are comparatively most abundant. When focussing on the role of water in trade, the first theory would consider relative water productivity (crop per drop), while the second theory would look at relative water abundance (Hoekstra, 2013). Part of the literature on water saving through international food trade has focussed on comparing water productivities among foodtrading countries (Chapagain et al., 2006; Yang et al., 2006; Oki et al., 2017), while other studies have concentrated on analysing food trade in relation to water endowments (Yang et al., 2003; Oki and Kanae, 2004; Chouchane et al., 2018). In a study for China, Zhao et al. (2019), evaluated spatiotemporal differences in the regional water, land and labour productivity of agricultural and non-agricultural sectors across Chinese provinces and defined comparative advantage on that basis. These comparative advantages were used to track the driving force of the virtual water regional trade. Their findings suggest that differences in land productivity were the main forces shaping the pattern of virtual water flows across Chinese regions, while neither labour nor water productivity had a significant influence.

In the current study, we consider, for the first time, how both differences in water productivity and water endowment can be considered to analyse comparative advantages of countries for different types of crop production. While doing so, we also consider differences between countries in land productivities (crop yields) and land endowments (available cropland areas).

Studies on the spatial allocation of crop production, given differences in land and water productivity and endowments, are sparse, particularly large-scale studies. In local or regional studies that study best crop choices given land and water constraints, the focus is generally to maximize food production or agricultural value, without the requirement of fulfilling overall crop demand. Osama et al. (2017), for example, employ a linear-optimization model for some regions in Egypt to maximize the net annual return by changing the cropping pattern, given water and land constraints, and conclude that some crops are to be expanded, while others are to be reduced. Another example of a regional study is Ye et al. (2018), who used a multi-objective-optimization model, considering the trade-offs between economic benefits and the environmental impact of water use when changing the cropping pattern in a case study for Beijing.

In a study for the US, Davis et al. (2017b) investigated alternative crop distribution that saves water and improves productivity while maintaining crop diversity, protein production and income. The only global study on changing cropping patterns in order to reduce water use, to our knowledge, is Davis et al. (2017a), who combine data on water use and productivity for 14 major crops and show that changing the distribution of these crops across the world's currently cultivated lands could decrease blue water use by $12 \%$ and feed an additional 825 million people. However, the current study has a number of differences compared with Davis et al. (2017a). First, we are only changing cropping patterns while maintaining the same global production per crop, whereas Davis et al. (2017a) aim for a higher caloric and protein production while reducing water use; that also results in a different global consumption pattern, which hampers the identification of potential water-saving effects of just production shifts amongst countries. Second, we consider a larger number of crops (125 crops including vegetables, fruits and pulses which were not considered in Davis et al., 2017a).

Although it has been widely acknowledged that the spatial water scarcity pattern in the world can be explained by where crops are grown and how much they are irrigated (Wada et al., 2011; Mekonnen and Hoekstra, 2016), it has not yet been studied how differences between countries in water and land productivities and endowments can be used to derive comparative advantages of countries for specific crops and how a change in the global cropping pattern can reduce water scarcity in the most water-scarce places. Here, we explore how we can stepwise minimize the highest national water scarcity in the world by changing cropping patterns and the related blue water allocation to crops. The spatial resolution of the country level reflects the coarse resolution at which the Food and Agriculture Organization of the United Nations (FAO) monitors and reports water stress in the Sustainable Development Goal (SDG) framework (FAO, 2018); subnational heterogeneity in water scarcity, which is significant in countries like the US or China, is not covered at this resolution. With cropping pattern we mean the allocation of crops to rainfed and irrigated land in all countries of the world, where both rainfed and irrigated areas of each crop in each country are allowed to expand up to a modest maximum rate (factor $\alpha$ ), while respecting the bounds of current total rainfed and total irrigated area per country as well as the global 
production per crop. For this purpose, we develop and apply a linear-programming-optimization algorithm considering a number of constraints. First, total rainfed and irrigated harvested areas in each country should not grow beyond their extent in the reference period of 1996-2005. Second, the harvested area per country per crop can only expand by a limited rate (which will be varied), both for the rainfed and irrigated area. Third, the global production of each crop must remain the same as in the reference period. The optimization takes into account both factor endowments (blue water availability, rainfed land availability and irrigated land availability) in each country and factor productivities (blue water productivity in irrigation and land productivities in rainfed and irrigated lands) for each crop in each country. In order to focus on aspects of natural-resource endowment and productivity in relation to water scarcity, other important aspects such as socioeconomic or national food self-sufficiency goals were not considered.

\section{Methods and data}

We developed a linear-optimization algorithm in MATLAB. In the optimization we allow the global cropping pattern to change, that is to grow crops in countries other than in the reference situation. In the optimization, the cropping areas by crop, country and production system are the independent variables, and the following constraints are considered. First, both total rainfed and total irrigated harvested areas per country are not allowed to expand. Second, both crop-specific rainfed and irrigated harvested area per country are allowed to expand but not beyond a factor $\alpha$ (whereby we stepwise increase $\alpha$ from 1.1 to 2.0 in a number of subsequent experiments). Third, the global production of each crop should remain equal to the global production of the crop in the reference situation. For any cropping pattern, the water scarcity in each country is computed, and the country with the highest water scarcity is identified. The objective of the optimization is to minimize the highest water scarcity. The algorithm continuously tries to reduce the blue water scarcity in the countries with the highest blue water scarcity while disallowing blue water scarcity in any country to increase. The algorithm will thus tend to reduce and equalize blue water scarcity in the most water-scarce countries.

We considered 125 crops of the main crops groups (cereals, fibres, fruits, nuts, oil crops, pulses, roots, spices, stimulants, sugar crops and vegetables; for an extensive list of crops used, see Chouchane et al., 2020); the optimization was performed using the linear-optimization routine from the Optimization Toolbox of MATLAB.

Given the cropping pattern, production is computed per country and crop, both for rainfed and irrigated lands based on the harvested area and crop yields:

$$
\begin{aligned}
& \forall i, j: P_{\mathrm{rf}}(i, j)=A_{\mathrm{rf}}(i, j) \times Y_{\mathrm{rf}}(i, j) \\
& \forall i, j: P_{\mathrm{ir}}(i, j)=A_{\mathrm{ir}}(i, j) \times Y_{\mathrm{ir}}(i, j) \\
& \forall i, j: P(i, j)=P_{\mathrm{rf}}(i, j)+P_{\mathrm{ir}}(i, j),
\end{aligned}
$$

whereby $P_{\mathrm{rf}}(i, j), P_{\mathrm{ir}}(i, j)$ and $P(i, j)$ are the rainfed, irrigated and total production in country $i$ of crop $j ; A_{\mathrm{rf}}(i, j)$ and $A_{\text {ir }}(i, j)$ are the rainfed and irrigated harvested area in country $i$ for crop $j$; and $Y_{\mathrm{rf}}(i, j)$ and $Y_{\mathrm{ir}}(i, j)$ are the rainfed and irrigated crop yield in country $i$ for crop $j$.

Blue water scarcity (BWS) is defined per country $i$ as the total blue water footprint divided by the blue water availability in the country (Hoekstra et al., 2012). The blue water footprint (BWF) refers to the volume of consumptive freshwater use for irrigation that comes from surface water and groundwater. Blue water availability is taken from FAO (2015) and refers to the total renewable amount (internal and external resources), which is the long-term average annual flow of rivers (surface water) and sustainably available groundwater (FAO, 2003).

$\operatorname{BWS}(i)=\frac{\sum_{j} P_{\mathrm{ir}}(i, j) \times \operatorname{BWF}(i, j)}{\mathrm{BWA}(i)}$,

where $P_{\mathrm{ir}}(i, j)$ is the irrigated production in country $i$ of crop $j, \operatorname{BWF}(i, j)$ is the blue water footprint per unit of crop $j$ in country $i$, and $\mathrm{BWA}(i)$ is the blue water availability in country $i$. A country is considered to be under low, moderate, significant or severe water scarcity when BWS (expressed as a percentage) is lower than $20 \%$, in the range of $20 \%-30 \%$, in the range of $30 \%-40 \%$ and larger than $40 \%$ respectively (Hoekstra et al., 2012).

The optimization can be presented as follows:

$\min _{A_{\mathrm{rf}}, A_{\mathrm{ir}}}\left(\max _{i}(\mathrm{BWS}(i))\right)$,

subject to

$$
\begin{aligned}
& \forall i: \sum_{j} A_{\mathrm{rf}}(i, j) \leq \sum_{j} A_{\mathrm{rf}, \mathrm{ref}}(i, j) \\
& \forall i: \sum_{j} A_{\text {ir }}(i, j) \leq \sum_{j} A_{\mathrm{ir}, \mathrm{ref}}(i, j) \\
& \forall i, j: A_{\mathrm{rf}}(i, j) \leq \alpha \times A_{\mathrm{rf}, \mathrm{ref}}(i, j) \\
& \forall i, j: A_{\mathrm{ir}}(i, j) \leq \alpha \times A_{\mathrm{ir}, \mathrm{ref}}(i, j) \\
& \forall j: \sum_{i} P(i, j)=\sum_{i} P_{\mathrm{ref}}(i, j) \\
& \forall i: \operatorname{BWS}(i) \leq \operatorname{BWS}_{\mathrm{ref}}(i),
\end{aligned}
$$

where $A_{\mathrm{rf}}(i, j)$ and $A_{\mathrm{ir}}(i, j)$ are the rainfed and irrigated harvested areas in country $i$ of crop $j$ in the cropping pattern that is varied in order to minimize the highest national blue water scarcity, $A_{\mathrm{rf}, \text { ref }}(i, j)$ and $A_{\mathrm{ir}, \text { ref }}(i, j)$ are the rainfed and irrigated harvested areas in the reference situation, $P(i, j)$ is the 
total (rainfed plus irrigated) production in country $i$ of crop $j$ in the new cropping pattern, $P_{\text {ref }}(i, j)$ is the total (rainfed plus irrigated) production in country $i$ of crop $j$ in the reference situation, and $\mathrm{BWS}_{\text {ref }}(i)$ is the blue water scarcity in country $i$ in the reference situation. Parameter $\alpha$ is the factor of the maximally allowed expansion of the harvested area per crop and country and production system (rainfed or irrigated), which is varied in the optimization experiments between 1.1 and 2. Note that total national croplands (both rainfed and irrigated) are not allowed to expand but that reductions in land use are always allowed.

A country is considered to have a comparative advantage for producing a certain crop or crop group when the following criteria are met: (1) the relative change (production in the optimized cropping pattern divided by the production in the reference situation) of that crop or crop group continues to increase in that country when we gradually increase the maximally allowed expansion of harvested area per crop per country (the factor $\alpha$ ) and (2) the share of the country in the global production of the crop or crop group exceeds $5 \%$ (in the optimized cropping pattern at $\alpha=1.1$ ).

In order to test the sensitivity of the optimization results to the allowed changes in irrigation, we run the optimization without allowing any expansion of the irrigated area. In this case, the factor $\alpha$ will be only applied to the rainfed area, while the irrigated area per country per crop will be below or equal to the irrigated area of the same crop in the same country in the reference situation. The optimization objective and constraints remain the same except that the following constraint was added:

$\forall i, j: A_{\text {ir }}(i, j) \leq A_{\text {ir,ref }}(i, j)$.

The sources of the data used to perform the optimization are summarized in Table 1.

\section{Results}

\subsection{Changes in blue water scarcity and blue water consumption}

When $\alpha$ is 1.1 , that means when we allow a maximum of $10 \%$ expansion of the reference harvested areas for each individual crop, in every country, both for rainfed and irrigated production, blue water scarcity in the world's seven most water-scarce countries, Libya, Saudi Arabia, Kuwait, Yemen, Qatar, Egypt and Israel (with current scarcities ranging from $54 \%$ to $270 \%$ ), is reduced to a scarcity of $39 \%$ or less (Table 2). In this scenario, the aggregated blue water footprint of crop production in the world is reduced by $21 \%$, while the total global harvested and irrigated areas are reduced by $2 \%$ and $10 \%$ respectively.

When $\alpha$ is equal to $1.3,1.5$ and 2.0 (i.e. when the maximally allowed expansion of harvested area per crop per country is equal to $30 \%, 50 \%$ and $100 \%$ ), the world's maximum national blue water scarcity is further reduced to $6 \%, 4 \%$ and $2 \%$ respectively. In these scenarios, global blue water consumption gets reduced by $38 \%, 48 \%$ and $60 \%$ respectively; the total global harvested area gets reduced by $6 \%$, $7 \%$ and $9 \%$ respectively, and the total global irrigated area gets reduced by $23 \%, 27 \%$ and $37 \%$ respectively.

Most countries with severe water scarcity (BWS > 40\%) in the reference situation show a moderate (BWS in the range of $20 \%-30 \%$ ) to low water scarcity (BWS $<20 \%$ ) in the optimized situation with $\alpha=1.1$ (Fig. 1). However, not all countries would benefit similarly in the optimized situation. China and India, major crops producers in the reference situation, only start to have a decrease in their BWS when $\alpha \geq 1.3$.

In the case of $\alpha=1.1$, Pakistan, the third-largest consumer of blue water in the reference situation, has the largest reduction in its blue water consumption in absolute terms, viz. $60000 \mathrm{~m}^{3} \mathrm{yr}^{-1}$, which represents $80 \%$ of its current BWC and $35 \%$ of the global blue water saving. Other countries that have a significant reduction in their BWC in absolute terms include Iran, Egypt, Iraq, Syria, Saudi Arabia, Sudan and Turkmenistan (Fig. 2). However, not all countries would benefit similarly in the optimized set. India and China, the first- and second-largest consumers of blue water in the reference situation, will only start to have a decrease in their blue water scarcity when the allowed expansion rate $\alpha$ is larger than 1.2 ; this is due to the optimization of water scarcity at the level of countries, where India and China have modest national water scarcity.

\subsection{The changing global cropping pattern for the case of $\alpha=1.1$}

The reduction of global blue water consumption is achieved by reallocating the most resource-intensive crops from countries that have lower productivity in terms of land and water to countries with significantly higher productivities, both for rainfed and irrigated production, thus reducing irrigation in countries that initially have a high BWS value. In the optimized cropping pattern, cereal production is reduced most significantly in Africa, relative to the reference situation, and South America and expanded in North America and Europe (Table 3). Irrigated cereal production is reduced in most of the world's regions (except for a small expansion in Europe and South America), whereas global rainfed production increases. For individual countries, Pakistan and Egypt have the largest decrease in total cereal production. The most significant expansions in cereal production are found in the US and China for maize; in China, India, the Russian Federation and France for wheat production; and in India, Indonesia and Vietnam for rice production. In terms of harvested area, the largest areal decrease in cereals is found in Asia, with a reduction of $8 \times 10^{6}$ ha in total (Table S1 in the Supplement), which represents $3 \%$ of the current harvested area of cereals in Asia. The irrigated area of cereals in Asia is reduced 
Table 1. Overview of data used.

\begin{tabular}{llll}
\hline Variable & Spatial resolution & Temporal resolution & Source \\
\hline Blue water availability & $\begin{array}{l}\text { Country (internal and exter- } \\
\text { nal } \\
\text { renewable water resources) }\end{array}$ & Average for 1961-1990 & FAO (2015) \\
\hline $\begin{array}{l}\text { Harvested irrigated and rainfed } \\
\text { land per crop in the reference } \\
\text { situation }\end{array}$ & Country & Average for 1996-2005 & $\begin{array}{l}\text { Mekonnen and Hoekstra } \\
(2011), \text { FAO (2015) }\end{array}$ \\
\hline $\begin{array}{l}\text { Rainfed and irrigated produc- } \\
\text { tion per crop in the reference } \\
\text { situation }\end{array}$ & Country & Average for 1996-2005 & $\begin{array}{l}\text { Mekonnen and Hoekstra } \\
(2011), \text { FAO (2015) }\end{array}$ \\
\hline $\begin{array}{l}\text { BWF per unit of crop in } \\
\text { irrigated production per crop }\end{array}$ & Country & Average for 1996-2005 & $\begin{array}{l}\text { Mekonnen and Hoekstra } \\
(2011)\end{array}$ \\
\hline $\begin{array}{l}\text { Yield in rainfed and irrigated } \\
\text { production per crop }\end{array}$ & Country & Average for 1996-2005 & $\begin{array}{l}\text { Mekonnen and Hoekstra } \\
(2011)\end{array}$ \\
\hline
\end{tabular}

Table 2. Current versus optimized blue water consumption (BWC) and blue water scarcity (BWS) for countries currently having a water scarcity value higher than $15 \%$.

\begin{tabular}{|c|c|c|c|c|c|c|c|c|c|c|}
\hline \multirow[t]{2}{*}{ Countries } & \multicolumn{2}{|c|}{ Current } & \multicolumn{2}{|c|}{ Optimized $(\alpha=1.1)$} & \multicolumn{2}{|c|}{ Optimized $(\alpha=1.3)$} & \multicolumn{2}{|c|}{ Optimized $(\alpha=1.5)$} & \multicolumn{2}{|c|}{ Optimized $(\alpha=2.0$ ) } \\
\hline & $\begin{array}{r}\text { BWC } \\
\left(10^{6} \mathrm{~m}^{3} \mathrm{yr}^{-1}\right)\end{array}$ & $\begin{array}{r}\text { BWS } \\
(\%)\end{array}$ & $\begin{array}{r}\text { BWC } \\
\left(10^{6} \mathrm{~m}^{3} \mathrm{yr}^{-1}\right)\end{array}$ & $\begin{array}{r}\text { BWS } \\
(\%)\end{array}$ & $\begin{array}{r}\text { BWC } \\
\left(10^{6} \mathrm{~m}^{3} \mathrm{yr}^{-1}\right)\end{array}$ & $\begin{array}{r}\text { BWS } \\
(\%)\end{array}$ & $\begin{array}{r}\text { BWC } \\
\left(10^{6} \mathrm{~m}^{3} \mathrm{yr}^{-1}\right)\end{array}$ & $\begin{array}{r}\text { BWS } \\
(\%)\end{array}$ & $\begin{array}{r}\text { BWC } \\
\left(10^{6} \mathrm{~m}^{3} \mathrm{yr}^{-1}\right)\end{array}$ & $\begin{array}{r}\text { BWS } \\
(\%)\end{array}$ \\
\hline Libya & 1900 & $270 \%$ & 210 & $30 \%$ & 41 & $6 \%$ & 25 & $4 \%$ & 16 & $2 \%$ \\
\hline Saudi Arabia & 6200 & $260 \%$ & 940 & $39 \%$ & 140 & $6 \%$ & 87 & $4 \%$ & 54 & $2 \%$ \\
\hline Kuwait & 48 & $240 \%$ & 8 & $39 \%$ & 1 & $6 \%$ & 1 & $4 \%$ & 0 & $2 \%$ \\
\hline Yemen & 2100 & $98 \%$ & 2.8 & $0 \%$ & 3 & $0 \%$ & 76 & $4 \%$ & 48 & $2 \%$ \\
\hline Qatar & 51 & $88 \%$ & 23 & $39 \%$ & 3 & $6 \%$ & 2 & $4 \%$ & 1 & $2 \%$ \\
\hline Egypt & 34000 & $57 \%$ & 3800 & $7 \%$ & 3400 & $6 \%$ & 2100 & $4 \%$ & 1300 & $2 \%$ \\
\hline Israel & 960 & $54 \%$ & 340 & $19 \%$ & 100 & $6 \%$ & 65 & $4 \%$ & 40 & $2 \%$ \\
\hline Jordan & 410 & $43 \%$ & 70 & $8 \%$ & 55 & $6 \%$ & 34 & $4 \%$ & 21 & $2 \%$ \\
\hline Syria & 7000 & $42 \%$ & 690 & $4 \%$ & 990 & $6 \%$ & 610 & $4 \%$ & 380 & $2 \%$ \\
\hline Oman & 550 & $39 \%$ & 550 & $39 \%$ & 82 & $6 \%$ & 51 & $4 \%$ & 32 & $2 \%$ \\
\hline Uzbekistan & 15000 & $31 \%$ & 13000 & $26 \%$ & 890 & $2 \%$ & 1800 & $4 \%$ & 1100 & $2 \%$ \\
\hline Cyprus & 240 & $31 \%$ & 59 & $8 \%$ & 46 & $6 \%$ & 28 & $4 \%$ & 18 & $2 \%$ \\
\hline Pakistan & 74000 & $30 \%$ & 15000 & $6 \%$ & 14000 & $6 \%$ & 9000 & $4 \%$ & 5600 & $2 \%$ \\
\hline Iran & 40000 & $29 \%$ & 8400 & $6 \%$ & 8000 & $6 \%$ & 5000 & $4 \%$ & 3100 & $2 \%$ \\
\hline Tunisia & 1300 & $29 \%$ & 530 & $11 \%$ & 270 & $6 \%$ & 170 & $4 \%$ & 100 & $2 \%$ \\
\hline Algeria & 2700 & $23 \%$ & 1900 & $16 \%$ & 690 & $6 \%$ & 430 & $4 \%$ & 260 & $2 \%$ \\
\hline Turkmenistan & 5300 & $21 \%$ & 520 & $2 \%$ & 620 & $3 \%$ & 900 & $4 \%$ & 560 & $2 \%$ \\
\hline Morocco & 5100 & $18 \%$ & 3100 & $11 \%$ & 1700 & $6 \%$ & 1100 & $4 \%$ & 660 & $2 \%$ \\
\hline Malta & 9 & $17 \%$ & 8 & $15 \%$ & 3 & $6 \%$ & 2 & $4 \%$ & 1 & $2 \%$ \\
\hline Lebanon & 770 & $17 \%$ & 730 & $16 \%$ & 260 & $6 \%$ & 160 & $4 \%$ & 100 & $2 \%$ \\
\hline Sudan & 6100 & $16 \%$ & 2100 & $6 \%$ & 2200 & $6 \%$ & 1400 & $4 \%$ & 860 & $2 \%$ \\
\hline Global & 820000 & & 650000 & & 510000 & & 430000 & & 330000 & \\
\hline
\end{tabular}

by $6 \%$ compared to the reference situation, while the rainfed area has an increase of $1 \%$. Africa has the second-largest decrease of the irrigated area of cereals with $3 \times 10^{6}$ ha and the largest increase of rainfed area of cereals with $2.6 \times 10^{6}$ ha. Changes in the global pattern of cereal production for the case of $\alpha=1.1$ contribute $50 \%$ to the total global reduction in the blue water footprint and $46 \%$ to the total global reduction in the irrigated area.
Fruit production is reduced most significantly in Asia and Africa and expanded in the Americas (Table 3). Major fruit production reductions include the decrease of apple production in Iran; banana production in Thailand; orange production in Egypt, Iran and Pakistan; and grape production in France. In North America, the most significant expansion in fruit production is the increase in orange, grape and apple production in the US; in South America, the largest fruit pro- 

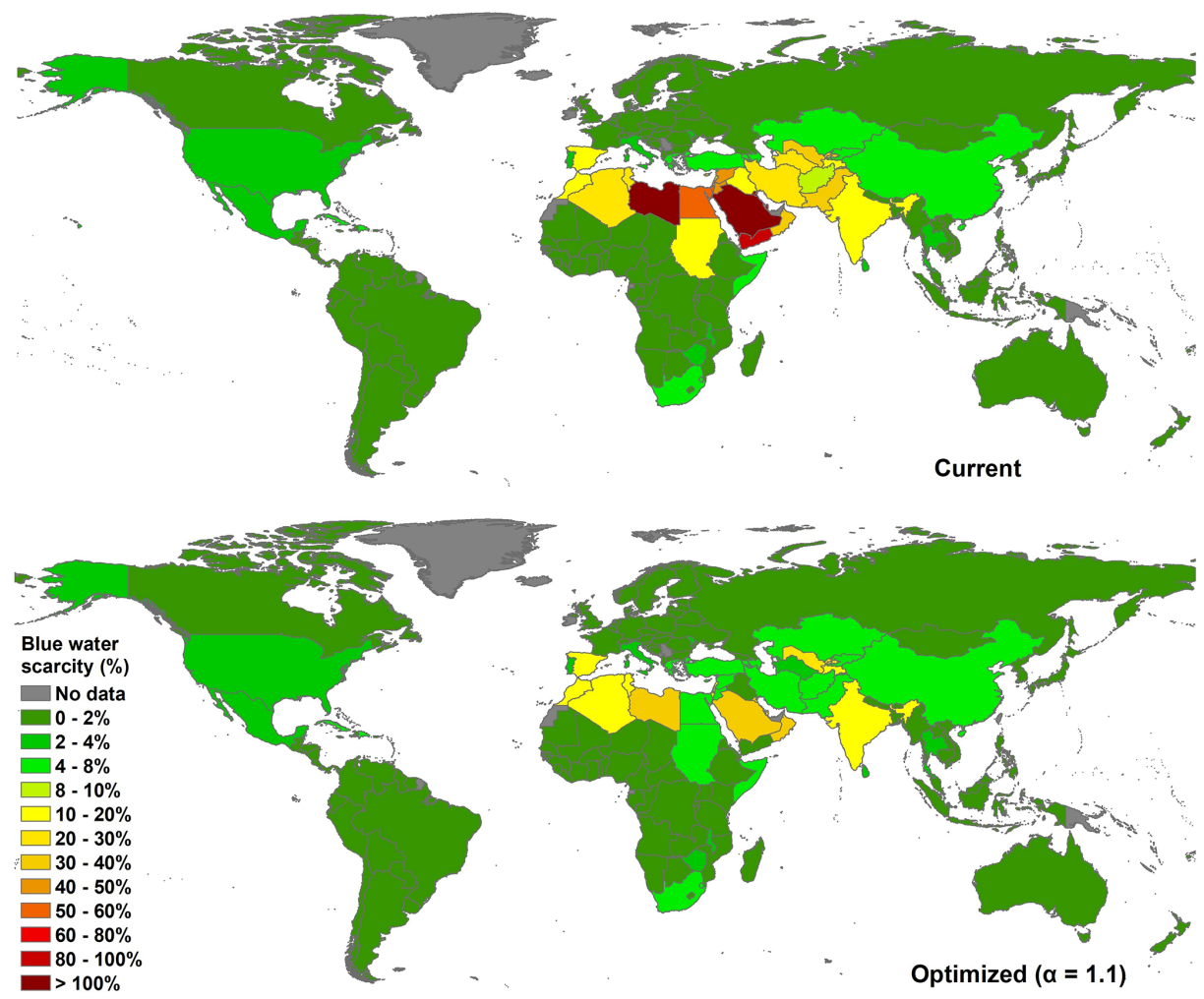

Figure 1. Current and optimized $(\alpha=1.1)$ blue water scarcity.
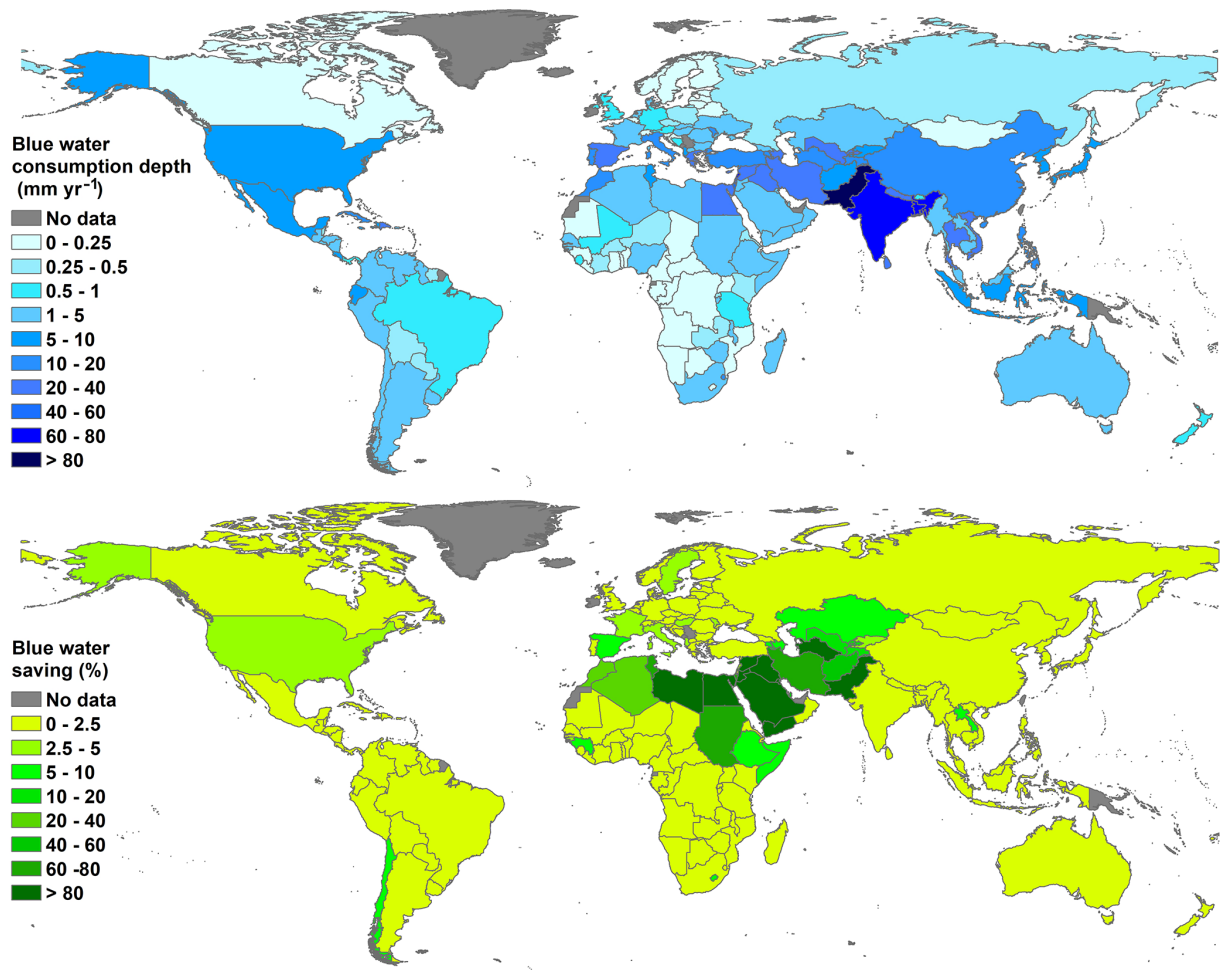

Figure 2. Current blue water consumption depth (in $\mathrm{mm} \mathrm{yr}^{-1}$ ) and blue water saving as a percentage of current BWC in the case of an optimized cropping pattern $(\alpha=1.1)$. 
Table 3. Change in production per product group per continent in absolute terms $\left(10^{6} \mathrm{t} \mathrm{yr}^{-1}\right)$ when shifting from the cropping pattern in the reference period (1996-2005) to the optimized cropping pattern (with $\alpha=1.1$ ).

\begin{tabular}{llrrrrrrrrrrr}
\hline & Cereal & Fibres & Fruits & Nuts & $\begin{array}{r}\text { Oil } \\
\text { crops }\end{array}$ & Pulses & Roots & Spices & Stimulants & $\begin{array}{r}\text { Sugar } \\
\text { crops }\end{array}$ & Vegetables \\
\hline Africa & Rainfed & 3.2 & 0.3 & 3.5 & 0.1 & -8.9 & 0.4 & 7.0 & 0.0 & 0.4 & 3.2 & 0.7 \\
& Irrigated & -17.2 & -0.7 & -5.8 & 0.0 & -1.3 & -0.3 & -4.0 & -0.1 & 0.0 & -21.8 & -9.5 \\
& Total & -14.0 & -0.3 & -2.3 & 0.1 & -10.2 & 0.1 & 2.9 & -0.1 & 0.4 & -18.6 & -8.9 \\
\hline Asia & Rainfed & 16.1 & 1.3 & 11.0 & 0.1 & 4.6 & -0.2 & 6.9 & 0.3 & 0.0 & 10.6 & 34.0 \\
& Irrigated & -14.5 & -2.6 & -19.2 & -0.2 & -8.3 & -0.2 & -4.9 & -0.2 & -0.2 & -61.4 & -13.8 \\
& Total & 1.6 & -1.3 & -8.2 & -0.1 & -3.7 & -0.4 & 1.9 & 0.1 & -0.2 & -50.8 & 20.1 \\
\hline Europe & Rainfed & 6.4 & 0.0 & -0.1 & 0.0 & 0.7 & -0.1 & -0.6 & 0.0 & 0.0 & 0.1 & -7.0 \\
& Irrigated & 0.8 & 0.2 & 1.3 & 0.0 & 0.5 & 0.1 & 1.8 & 0.0 & 0.0 & 3.1 & -2.4 \\
& Total & 7.2 & 0.1 & 1.2 & 0.0 & 1.2 & -0.1 & 1.3 & 0.0 & 0.0 & 3.3 & -9.5 \\
\hline North & Rainfed & 11.6 & 0.6 & 1.2 & 0.0 & 5.1 & 0.5 & -0.9 & 0.0 & -0.2 & 8.9 & -1.0 \\
America & Irrigated & -0.7 & 0.5 & 3.5 & 0.1 & 0.4 & 0.1 & 1.7 & 0.0 & 0.0 & 8.2 & -0.7 \\
& Total & 10.9 & 1.1 & 4.7 & 0.1 & 5.5 & 0.6 & 0.9 & 0.0 & -0.2 & 17.1 & -1.7 \\
\hline Oceania & Rainfed & 0.4 & 0.0 & 0.1 & 0.0 & 0.1 & -0.3 & -0.1 & 0.0 & 0.0 & 1.1 & -0.1 \\
& Irrigated & -0.3 & 0.1 & -0.1 & 0.0 & 0.0 & 0.0 & 0.1 & 0.0 & 0.0 & 2.9 & 0.1 \\
& Total & 0.1 & 0.1 & -0.1 & 0.0 & 0.1 & -0.3 & 0.1 & 0.0 & 0.0 & 4.0 & 0.0 \\
\hline South & Rainfed & -6.3 & 0.3 & 4.1 & 0.0 & 6.9 & 0.0 & -7.2 & 0.0 & 0.0 & 35.4 & -0.3 \\
America & Irrigated & 0.6 & 0.0 & 0.6 & 0.0 & 0.1 & 0.0 & 0.2 & 0.0 & 0.0 & 9.6 & 0.3 \\
& Total & -5.7 & 0.3 & 4.7 & -0.1 & 7.0 & 0.1 & -7.0 & 0.0 & 0.0 & 45.0 & 0.0 \\
\hline
\end{tabular}

duction increases are for oranges in Brazil and bananas in Ecuador. Although the reduction in fruit production in Asia and Africa mainly concerns irrigation, the irrigated production of fruits increases in North America and Europe. The largest share of increase in the irrigated production in North America comes from the increase in irrigated production of oranges, apples and grapes in the US. The world's harvested area of fruits reduces by $2 \%$. The irrigated area reduces by $19 \%$, while the rainfed area increases by $4 \%$. Changes in fruit production contributed $12 \%$ to global blue water savings and $9 \%$ to total global reductions in irrigated area.

The production of oil crops is reduced most significantly in Africa (e.g. oil palm in Nigeria) and expanded in the Americas (e.g. soybeans in the US, Brazil and Argentina). The harvested area shrinks globally by $3 \%$ in total. The irrigated area reduces by $30 \%$, although the global rainfed area remains the same as the reference situation. Asia and Africa have the most significant shrinkage in harvested areas of oil crops. Reallocating oil crops contributed $7 \%$ to global reductions in blue water footprint and $19 \%$ to total global reductions in irrigated area.

Root production partly moves from South America to Africa, Asia and Europe. At the country level, the most significant reduction is due to the decrease of potato production in Poland and Iran and cassava production in Brazil, China and Vietnam. The largest expansions are sweet potato production in China, potato production in the Russian Federation and cassava and yam production in Nigeria. Globally, the harvested area of roots is reduced by $4 \%$ (11\% for irrigated and $3 \%$ for rainfed croplands).

Sugar crop production is reduced most significantly in Asia and Africa and expanded in the Americas. Sugar cane production is mainly reduced in Pakistan, India and Egypt and expanded in Brazil. The global irrigated harvested area of sugar crops is reduced in total by $10 \%$, while the global rainfed area increases by $8 \%$. Changes in sugar crop production contribute $10 \%$ to the total blue water savings globally.

Vegetable production is reduced most significantly in Europe and Africa and expanded in Asia. Major reductions in vegetable production are for tomato production in Iran and Egypt. The most significant expansions are the increases in tomato and watermelon production in China. The global harvested area of vegetables is reduced by $4 \%$, with a reduction of $17 \%$ for irrigated croplands, while the rainfed area remains the same as reference situation. Reallocating vegetables contributed $5 \%$ to global reductions in the blue water footprint and $7 \%$ to global reductions in the total irrigated harvested area globally.

Although the cereal rainfed harvested area is reduced in North America when $\alpha=1.1$, for example (Table S1), rainfed cereal production will increase by $11.6 \times 10^{6} \mathrm{t} \mathrm{yr}^{-1}$. This illustrates that by allocating production to more productive countries, we can reduce water and land use and increase production at the same time. 


\subsection{Comparative advantages}

We explore the comparative advantages of countries to contribute to the goal of relieving global water scarcity. In the following, we use the term "comparative advantage" to indicate a comparative advantage for this specific goal, as that is where results from the study provide insight in; comparative advantages to e.g. contribute to increasing agroeconomic revenue or reducing the agricultural carbon footprint could result in different conclusions. Our exploration of comparative advantage is considering which crops in a country are expanding when we gradually move from $\alpha=1.1$ to $\alpha=1.5$. As a summary, Fig. 3 shows at the level of continents and crop groups, the relative change in total production when we move from the reference cropping pattern (1996-2005) along the optimized cropping pattern, considering a stepwise increase in the maximally allowed expansion rate in harvested area per crop per country from $\alpha=1.1$ to $\alpha=1.5$. Most of the changes in production that already occur for the modest areal-expansion rate per crop of $10 \%$ (Table 3 ) will continue under larger expansion rates, with some exceptions. This is, for example, the case for fibres in Europe and oil crops in North America. Fibre production expands for the case of $\alpha=1.1,1.2$ and 1.3 in Europe but again reduces for higher expansion rates. This can be explained by the fact that even more suitable regions, namely Oceania, North America and to a lesser extent Africa, continue expanding fibre production, allowing Europe to rather focus on cereal, sugar crop and stimulant production (Fig. 3). North America expands oil crop production when $\alpha=1.1$ (Table 3) but decreases oil crop production when $\alpha=1.2$ and has the largest reduction in oil crop production for $\alpha=1.5$ (Table S1). The reason behind this is that for the smallest expansion rate, the US still needs to produce oil crops, and the global production could not be reached without the expansion of oil crops in the US, which limits the allocation of harvested areas to more suitable crops in the US such as maize and sugar crops. From $\alpha=1.2$, the US will focus on producing maize in which they have a comparative advantage and give up a part of oil crop production. This example for North America shows that it is hard to have a robust conclusion on comparative advantages by looking at the level of continents. In order to explore comparative advantages, we will need to look at the country level. Figures 4 and 5 show the absolute and relative changes in production per crop group per country when we move from the cropping pattern in the reference situation to the optimized cropping pattern with $\alpha=1.5$.

\subsubsection{Cereal production}

The US and to a lesser extent Indonesia and France have large absolute and relative changes (Fig. 4) for cereals and thus a comparative advantage (given the combination of their water endowments and water productivities compared to other countries). In the case of $\alpha=1.5$, the cereal production of the
US, Indonesia and France will increase by $30 \%, 26 \%$ and $23 \%$ respectively compared to the reference situation. India has a comparative disadvantage in cereals and will reduce its production by $40 \%$ in the optimized cropping pattern with $\alpha=1.5$. Looking at the main cereal crops separately (wheat, barley, maize and rice) and combining information on relative and absolute changes, we find that France and the Russian Federation have a comparative advantage in wheat production, with large absolute increases when we optimize the global cropping pattern (Fig. S1). India and China, contributing $12 \%$ and $17 \%$ respectively of global wheat production in the reference period, have a comparative disadvantage and shrink their wheat production by $41 \%$ (for China) and $26 \%$ (for India) when $\alpha=1.5$. For barley, we find Canada, France, Spain and Turkey to have a comparative advantage. Germany and the Russian Federation, contributing $9 \%$ and $11 \%$ respectively to the global barley production in the reference period, have a comparative disadvantage and will decrease their barley production respectively by $28 \%$ and $88 \%$ when $\alpha=1.5$. For maize, the US is found to have a comparative advantage, while, Brazil, contributing $6 \%$ to global maize production in the reference period, has a comparative disadvantage and will reduce its maize production with $64 \%$ in the optimized situation $(\alpha=1.5)$. For rice, China, Indonesia and Vietnam have a comparative advantage, with shares in global rice production raising from $32 \%, 9 \%$ and $5 \%$ respectively in the reference situation to $22 \%, 29 \%$ and $27 \%$ in the optimized situation (when $\alpha=1.5$ ). India, contributing $22 \%$ to global rice production in the reference period, has a comparative disadvantage and will decrease its rice production by $43 \%$ when $\alpha=1.5$ compared to the reference situation.

\subsubsection{Fruit production}

Comparative advantages for fruit production are found for Brazil and the US, which will increase their respective shares in global fruit production from $7 \%$ and $6 \%$ in the reference situation to $11 \%$ and $9 \%$ in the optimized cropping pattern (when $\alpha=1.5$ ). China and India, contributing $14 \%$ and $10 \%$ respectively to global fruit production in the reference period, appear to have a comparative disadvantage and will reduce their fruit production by $13 \%$ and $31 \%$ respectively in the optimized situation (when $\alpha=1.5$ ). Zooming in to the top four produced fruits - apples, bananas, grapes and oranges we find the following. For apples, the US has a comparative advantage; the country will increase its share in global apple production from $8 \%$ (reference) to $12 \%$ (when $\alpha=1.5$ ). China, contributing $35 \%$ to the global apple production in the reference period, has a comparative disadvantage and will decrease its apple production by $12 \%$ in the optimized cropping patterns (when $\alpha=1.5$ ). For bananas, Ecuador, Brazil and the Philippines have a comparative advantage. India, contributing $22 \%$ to global banana production in the reference period, has a comparative disadvantage. For grapes, Italy, the US and China have a comparative advantage, with 

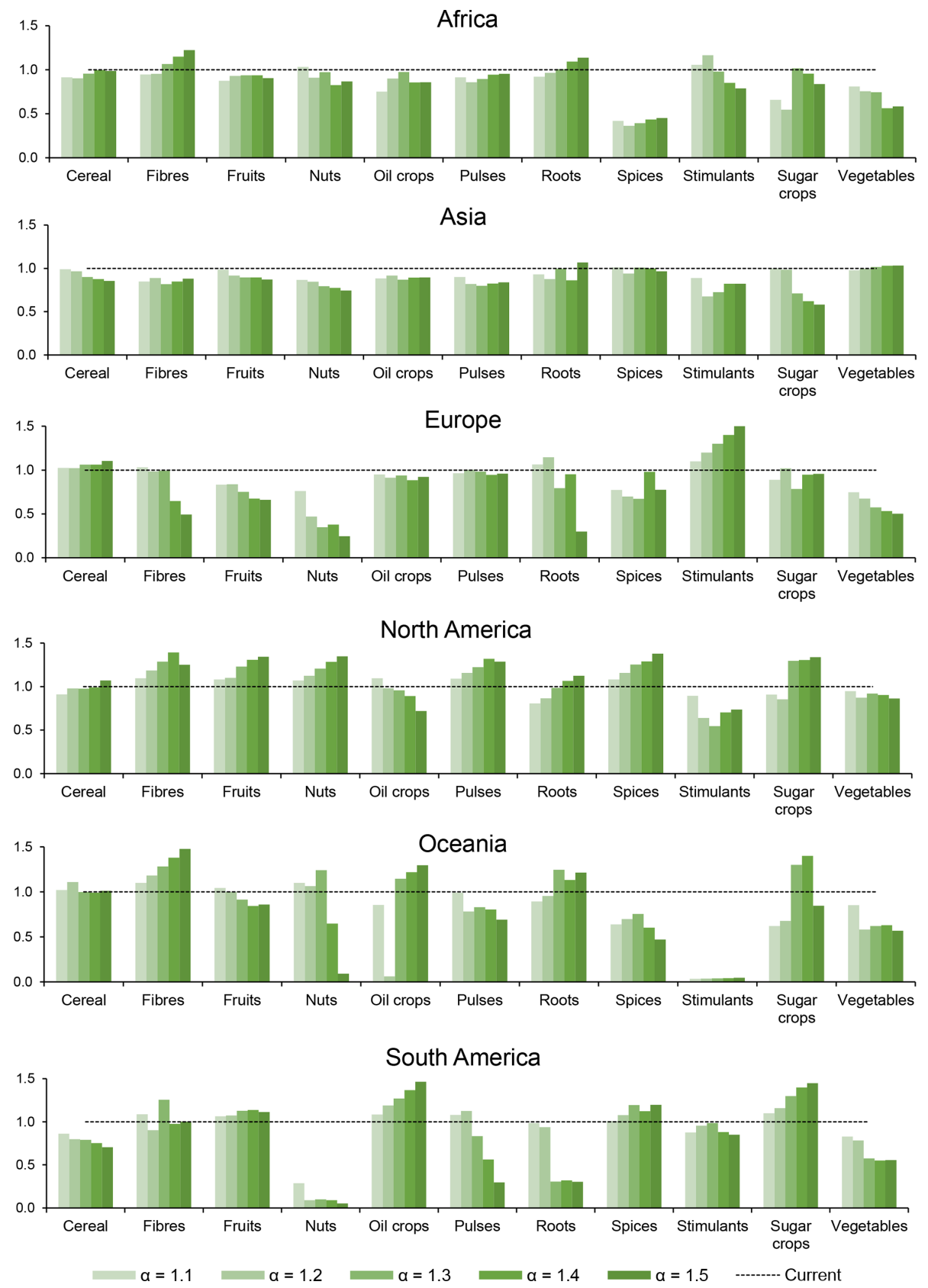

Figure 3. Ratio of total production in the optimized cropping pattern to total production in the reference cropping pattern (1996-2005), per crop group and per continent, for $\alpha=1.1$ to $\alpha=1.5$.

shares in global grape production rising from $15 \%, 9 \%$ and $7 \%$ (reference) to $22 \%, 13 \%$ and $10 \%(\alpha=1.5)$. France and Spain, contributing $13 \%$ and $9 \%$ respectively to global grape production in the reference situation, have a comparative disadvantage and will entirely abandon grape production when $\alpha=1.5$. For oranges, Brazil and the US have a comparative advantage, while Mexico, Spain and Iran have a comparative disadvantage (Fig. S2).

\subsubsection{Oil crops}

For oil crops, we find Indonesia, Brazil and Argentina to have a comparative advantage. Their shares in global oil crop production will raise from $13,9 \%$ and $6 \%$ respectively (reference) to $16 \%, 13 \%$ and $9 \%(\alpha=1.5)$. The US and Malaysia, contributing $17 \%$ and $12 \%$ respectively to global oil crop production in the reference situation, have a comparative disadvantage and will reduce their oil crop production by $32 \%$ and $14 \%$ respectively in the optimized cropping 

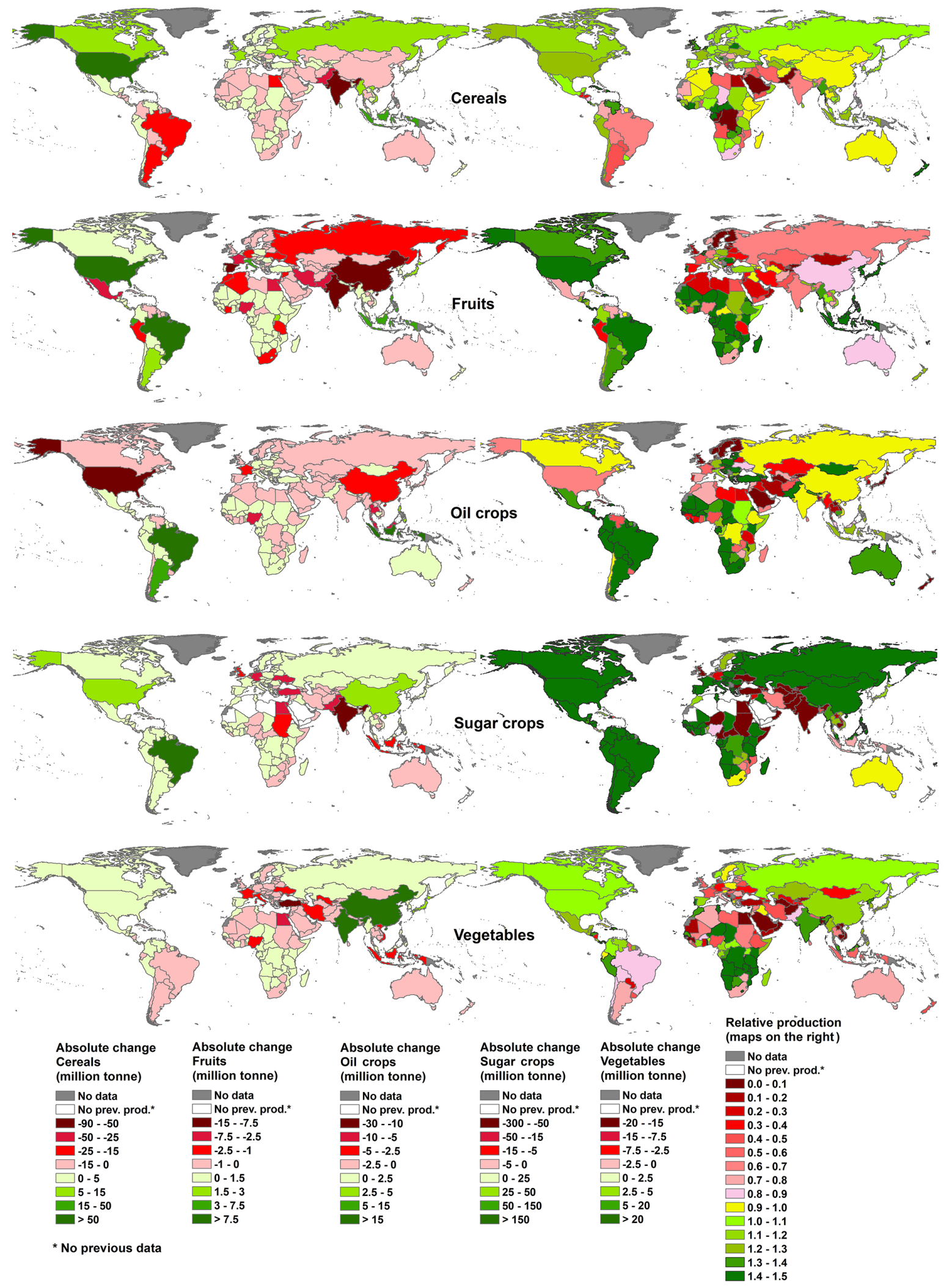

Figure 4. Absolute change in production for cereals, fruits, oil crops, sugar crops and vegetables per country (in $10^{6} \mathrm{tyr}^{-1}$; maps on the left) and relative production (ratio of production in optimized and reference situation) for the same crops groups for the case of an optimized cropping pattern with $\alpha=1.5$ (maps on the right), all compared to the reference cropping period (1996-2005). Relative production $=1$ : no change; relative production $<1$ : national production is reduced; relative production $>1$ : national production is expanded. 


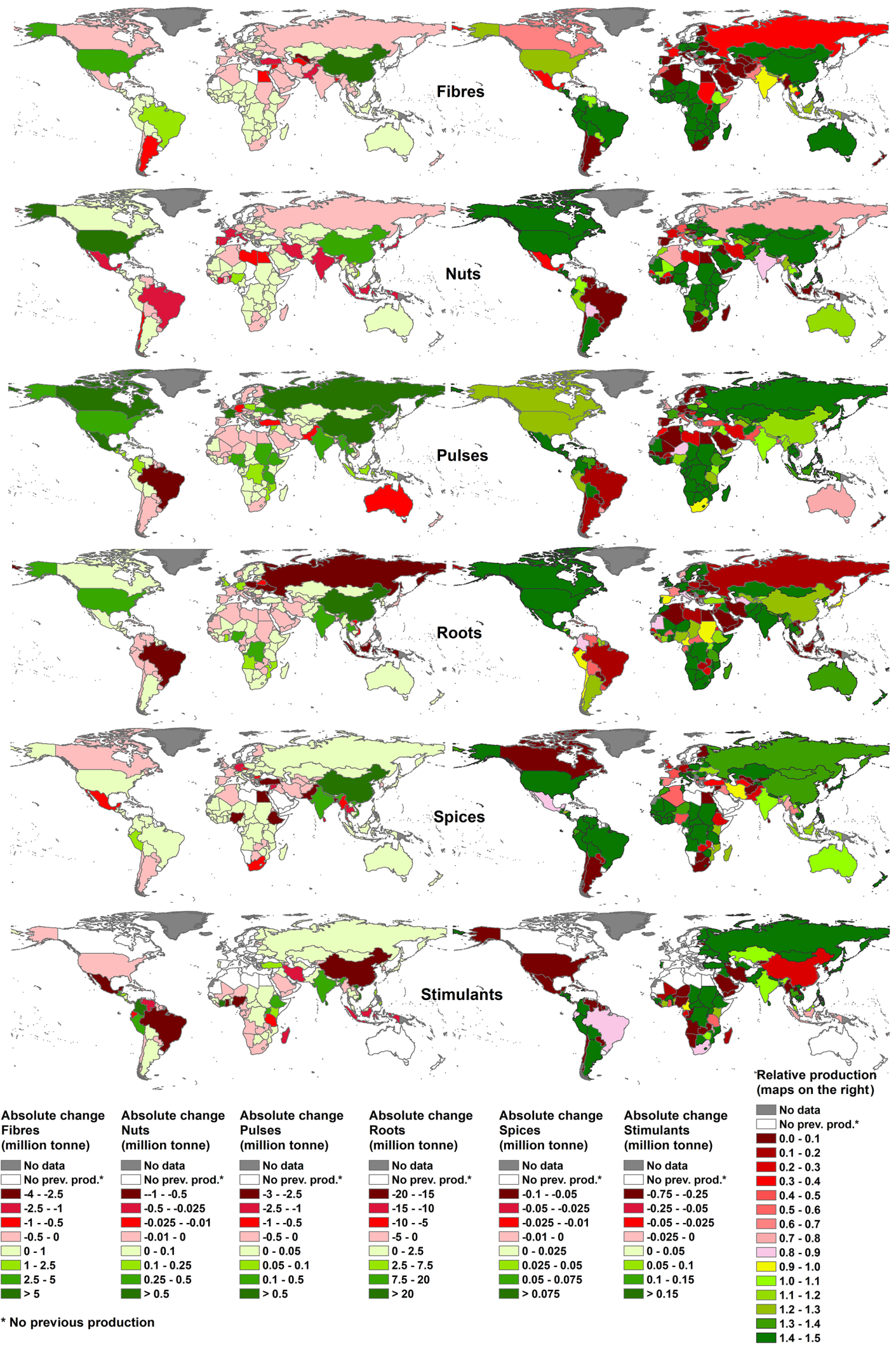

Figure 5. Absolute change in production for fibres, nuts, pulses, roots, spices and stimulants per country (in $10^{6} \mathrm{t} \mathrm{yr}^{-1}$; maps on the left) and relative production (ratio of production in optimized and reference situation) for the same crops groups for the case of an optimized cropping pattern with $\alpha=1.5$ (maps on the right), all compared to the reference cropping period (1996-2005). Relative production $=1$ : no change; relative production $<1$ : national production is reduced; relative production $>1$ : national production is expanded. 
pattern (when $\alpha=1.5$ ). Focussing on soybean, which contributes $36 \%$ to the global oil crop production, we find the comparative advantage for Argentina and Brazil. The share of Argentina and Brazil in global soybean production will rise from $14 \%$ and $22 \%$ respectively (reference) to $21 \%$ and $33 \%(\alpha=1.5)$. China and the US have a comparative disadvantage in soybean production. While the US, contributing $43 \%$ to the global soybean production in the reference period, will reduce its production by $31 \%$, China, contributing $9 \%$ in the reference period, will entirely stop its soybean production in the optimized pattern (when $\alpha=1.5$; Fig. S3).

\subsubsection{Sugar crops}

Brazil and China have a comparative advantage in sugar crop production, with shares in global sugar crop production rising from $23 \%$ and $6 \%$ respectively (reference) to $35 \%$ and $9 \%$ (optimized cropping pattern with $\alpha=1.5$ ). India, currently contributing $18 \%$ to the global sugar crop production, has a comparative disadvantage and will quit sugar crop production almost entirely. Considering sugar beet and sugar cane separately, we find that France, Poland, the Russian Federation and the US have a comparative advantage in sugar beet production. Germany, Turkey and Ukraine, contributing $11 \%, 7 \%$ and $6 \%$ to the global sugar beet production (reference), have a comparative disadvantage and will decrease their sugar beet production by $72 \%, 100 \%$ and $94 \%$ respectively (when $\alpha=1.5$ ). For sugar cane, Brazil and China have a comparative advantage; their shares in global sugar cane production will increase from $28 \%$ and $6 \%$ respectively (reference) to $42 \%$ and $10 \%$ (optimized cropping pattern with $\alpha=1.5$ ). India, contributing $22 \%$ to global sugar cane production in the reference period, has a comparative disadvantage and will decrease its sugar cane production by almost $100 \%$ (Fig. S3).

\subsubsection{Vegetables}

China and India have a comparative advantage in vegetable production. Their shares in global vegetable production will rise from $45 \%$ and $9 \%$ respectively (reference) to 52 and $12 \%$ respectively (optimized cropping pattern with $\alpha=1.5$ ). Turkey, contributing $4 \%$ to global vegetable production in the reference, has a comparative disadvantage and will reduce its vegetable production by $83 \%$ in the optimized pattern (when $\alpha=1.5$ ) compared to the reference situation. Looking at the most produced vegetable crop, tomato, which contributes $15 \%$ to global vegetable production, we find that China and the US have a comparative advantage (Fig. S3). The share of China and the US in the global production of tomatoes will increase from $21 \%$ and $11 \%$ respectively (reference) to $30 \%$ and $16 \%$ respectively (when $\alpha=1.5$ ). Egypt and Turkey, contributing $6 \%$ and $8 \%$ to global tomato production in the reference, have a comparative disadvantage and will stop their production almost entirely in the optimized situation.

\subsection{Sensitivity to restricting expansion to rainfed areas}

By allowing only rainfed areas per crop to expand up to $10 \%$ and the irrigated area per crop only to shrink, global blue water consumption of crop production is reduced by $16 \%$. When $\alpha$ is equal to $1.3,1.5$ and 2.0 (i.e. when harvested area per crop per country can expand by up to $30 \%, 50 \%$ and $100 \%$ ), global blue water consumption gets reduced by $31 \%, 41 \%$ and $54 \%$ respectively. The maximum blue water scarcity is reduced to a scarcity of $62 \%, 14 \%, 5 \%$ and $3 \%$ when $\alpha$ is equal to $1.1,1.3,1.5$ and 2.0 respectively (Table 4 ).

The shifts in only the rainfed area give a dominant contribution to the reduction of the maximum BWS value when allowing both rainfed and irrigated areas to expand. Contributions from only rainfed areas shifts amount to $90 \%$ of the total reduction when $\alpha$ is equal to 1.1 to $97 \%, 99 \%$ and $99.6 \%$ when $\alpha$ is equal to $1.3,1.5$ and 2.0 respectively. The dominance effect of shifts in rainfed areas proves that the optimization results are not very sensitive to modestly allowed expansion in irrigated areas per crop.

\section{Discussion}

Our study has some limitations that need careful consideration when interpreting results. Limited by the availability of some of the required data and operational computational limitations of optimization software, we analyse the global cropping pattern at the country scale rather than at subnational or grid scale. However, having a high average yield for a specific crop in a certain country does not necessarily mean that everywhere in that country the same performance in terms of land and water productivity is achieved, due to spatial differences in crop suitability. This could result in reallocating crops to countries that have a very limited suitable production area but are productive in terms of water and land in the reference situation. To constrain this effect, we do not allow total cropland per country to expand so that areal expansion for one crop replaces the land use of another crop with a shrinking area; also, we limit the expansion in cropland by a certain maximum rate for each crop per country (the factor $\alpha$ ). The analysis at the country level also has implications for the interpretability of water scarcity indicators. Assessing water scarcity at the country level for an average year hides the water scarcity that manifests itself in particular places within countries or in particular periods (Mekonnen and Hoekstra, 2016). We minimize average water scarcity in countries; within countries scarcity differences will still appear, both in the reference situation and in the case of the optimized cropping patterns. Still, water scarcity indicators at national levels provide insight; within the framework of the Sustainable Development Goals, indicator 6.4.2 ("Level 
Table 4. Current versus optimized maximum BWS when allowing both irrigated and rainfed areas to expand and when allowing only rainfed areas to expand and the share of rainfed areas shifts in reducing maximum BWS for the case when $\alpha$ is equal to $1.1,1.3,1.5$ and 2.0 respectively.

\begin{tabular}{|c|c|c|c|c|c|c|}
\hline \multirow[t]{3}{*}{ Factor $\alpha$} & \multicolumn{3}{|c|}{ Maximum BWS } & \multirow{2}{*}{\multicolumn{2}{|c|}{$\begin{array}{l}\text { Reduction in maximum BWS } \\
\text { compared to reference situation }\end{array}$}} & \multirow{3}{*}{$\begin{array}{r}\text { Share of rainfed } \\
\text { shifts in reducing } \\
\text { maximum BWS }\end{array}$} \\
\hline & \multirow[t]{2}{*}{ Current* } & \multicolumn{2}{|c|}{ Optimized } & & & \\
\hline & & $\begin{array}{r}\text { Expansion in both } \\
\text { irrigated and } \\
\text { rainfed areas }\end{array}$ & $\begin{array}{l}\text { Expansion only } \\
\text { in rainfed areas }\end{array}$ & $\begin{array}{r}\text { Expansion in both } \\
\text { irrigated and } \\
\text { rainfed areas }\end{array}$ & $\begin{array}{l}\text { Expansion only } \\
\text { in rainfed areas }\end{array}$ & \\
\hline$\alpha=1.1$ & $272 \%$ & $39 \%$ & $62 \%$ & $-86 \%$ & $-77 \%$ & $90 \%$ \\
\hline$\alpha=1.3$ & $272 \%$ & $6 \%$ & $14 \%$ & $-98 \%$ & $-95 \%$ & $97 \%$ \\
\hline$\alpha=1.5$ & $272 \%$ & $4 \%$ & $5 \%$ & $-99 \%$ & $-98 \%$ & $99 \%$ \\
\hline$\alpha=2.0$ & $272 \%$ & $2 \%$ & $3 \%$ & $-99 \%$ & $-99 \%$ & $99.6 \%$ \\
\hline
\end{tabular}

* Independent of $\alpha$.

of water stress") is used to monitor Goal 6 ("Ensure availability and sustainable management of water and sanitation for all"). It is defined similar to water scarcity in our study, also at the resolution of countries, but based on water extractions rather than consumptive water use. While lowering the water stress level is a goal for each country, from a global equity perspective lowering stress in countries with the highest water scarcity is prioritized. This is operationalized by choosing the maximum national water scarcity as an objective function in the optimization. Relieving water scarcity in specific hotspots within countries by changing cropping patterns could be studied using the current approach but is beyond the scope of this paper. The sensitivity analysis did show that by far the largest impact on water scarcity relief emerges from shifts in cropping patterns of rainfed crops, not depending on the heterogeneity of blue water availability; therefore water scarcity reduction in countries with the highest scarcity at the national level in the current study does not rely on worsening water scarcity in countries with heterogeneous conditions.

Another limitation of this study is the focus on water and land endowments and productivities and on global water scarcity reduction as a shared goal, while other production factors such as labour, knowledge, technology and capital can be limiting factors to expanding the production of certain crops in some countries, and certainly, agroeconomic aspects may play a role in considering comparative advantages as well. Other factors could be included in a future study by refining the optimization model; other objective functions could emphasize trade-offs between economic and environmental goals. Moreover, agricultural, trade and food security policies could be other factors that drive cropping patterns rather than water and land availability (Davis et al., 2018). Here, we purposely limited our analysis to considering comparative advantages from a perspective of land and water resource use to understand the specific role of these two particular factors. By no means do we suggest that the optimized cropping patterns found here are better than the reference pattern, because what is best depends on many more factors than are included here, including political preferences. Rather, our results are instrumental in illustrating directions of change if we would put emphasis on the factors of land and water endowment and productivity and put particular value on reducing water scarcity in the most water-scarce places.

The scope of the current study is restricted to the exploration of alternative cropping patterns to reduce water scarcity in the reference situation; we therefore use reference resource efficiencies. We do not take into consideration the future increase in food demand due to population growth, agronomic developments that may increase resource use efficiencies or climate change that will affect the future ability of countries to produce crops. The current study supports the findings of Davis et al. (2017a) on the benefits of crop redistribution on water saving which could be a potential strategy for sustainable crop production and an alternative to the large investments that are usually needed to close up the technological and yield gaps in developing nations. Besides reducing water and land use, changing cropping patterns will also have an impact on reducing greenhouse gas emission that results from extensive energy activities in irrigation, such as groundwater pumping, which accounted for around $61 \%$ of total irrigation emissions in China (Zou et al., 2015).

The results suggest that Asia, for example, could contribute to global water scarcity mitigation by reducing its production of fruits and sugar crops while increasing its cereal and vegetable production. This implies that Asia will move to economically less attractive crops. This illustrates the possible trade-off between the goal of reducing water scarcity in the most water-scarce countries and the goal of economic profit by producing cash crops by individual countries or regions. The optimization results do not pretend that the changes in production patterns are likely to occur but merely that these changes reduce water scarcity most; national and international policies would be required to pro- 
mote such water-saving changes to be implemented (Klasen et al., 2016).

Changing cropping patterns could reduce the global blue water footprint by $21 \%$ and global irrigated area by $10 \%$. These findings prove that current high scarcity levels in a serious number of countries are shown to be caused by the current crop allocation pattern rather than by an inevitability of those scarcities to occur; that suggests that water endowment is insufficiently driving crop allocation to avoid water scarcity. This in consistent with Zhao et al. (2019) who find in their study for China that comparative advantages with respect to labour and water were not reflected in the regional distribution of agricultural production. However, not all countries would benefit similarly in the optimized set. India and China, the main crop producers in the reference situation, will only start to have a decrease in their blue water scarcity when the allowed expansion rate is larger than $20 \%$. This is in line with the findings of Davis et al. (2017a), who find in their simulations that water scarcity persists in many important agricultural areas (the US Midwest, northern India and Australia's Murray-Darling basin, for example), indicating that extensive crop production in these places prohibits water sustainability, regardless of crop choice (Davis et al., 2017a).

Findings suggest that China, one of the world's main producers of the major crop, will abandon soybean production and halve wheat irrigation area. This will relieve some of the pressure on the northern part of China, where water scarcity is the most severe (Ma et al., 2020). China will increase the harvested area of rice and rapeseed, the crops with the most significant comparative advantage in terms of land and water. Similarly, our results suggest that the US, another major crop producer, would restrict soybean production to rainfed systems, abandoning irrigation, in the optimized set in the US. The US focuses on producing maize, mainly rainfed, for which the US has a comparative advantage in terms of water and land productivities. This may be a great relief to the US Corn Belt, where most of the irrigated soybean and maize crops are located (Zhong et al., 2016), and could be a remedy to the projected water shortage of that region resulting from population growth and climate change (Brown et al., 2019). We also find that India, another of the world's major producers of crops, will move away from sorghum production and shift a large share of its rice and wheat production to rainfed conditions. Moving to rainfed production in India could mitigate the effect of the intensive use of irrigation from groundwater and surface water which caused groundwater degradation in many districts of Haryana and Punjab, the largest contributing states to rice and wheat production in India (Singh, 2000).

For some of the most water-scarce countries, results show that blue water consumption in crop production is reduced by more than $70 \%$ compared to the reference situation: Cyprus, Egypt, Iran, Jordan, Kuwait, Libya, Pakistan, Saudi Arabia, Syria, Turkmenistan and Yemen. This means that these coun- tries, with modest rainfed agricultural areas, will rely more heavily on imports and thus become highly dependent on other countries. Most of these countries already have a high dependency on crop imports in the reference situation. This reflects a trade-off between reducing water scarcity and increasing food security on the one hand and shows the important role of food trade in relieving water scarcity in many places in the world on the other.

\section{Conclusion}

When allowing a $10 \%$ maximum expansion of harvested area per crop and per country, while not allowing an increase in the total rainfed or irrigated cropland per country, a global blue water saving of $17 \times 10^{10} \mathrm{~m}^{3} \mathrm{yr}^{-1}$ is achievable, which is $21 \%$ of the current global blue water footprint. Changes in the cropping pattern of rainfed production have a dominant effect, relieving irrigated areas to contribute to production; the total global harvested area would decrease by $2 \%$, and the total global irrigated area would decrease by $10 \%$. The blue water scarcity in the seven countries with highest national water scarcity, Libya, Saudi Arabia, Kuwait, Yemen, Qatar, Egypt and Israel (with current scarcities ranging from $54 \%$ to $270 \%$ ), can be reduced to a scarcity of $39 \%$ or less. Optimizing the global cropping pattern to reduce the highest national water scarcity comes with trade-offs, where severely water-scarce countries reduce water scarcity at the expense of decreased food self-sufficiency.

When considering how to change the global cropping pattern in order to reduce water scarcity in the world's most severely water-scarce countries, we specifically find the following major shifts. Cereal production is reduced in Africa and South America and increased in North America and Europe. Fruit production is reduced most significantly in Asia and Africa and expanded in the Americas. Oil crop production is reduced most significantly in Africa and expanded in the Americas. Sugar crop production is reduced most significantly in Asia and Africa and expanded in the Americas. Vegetable production is reduced most significantly in Europe and Africa and expanded in Asia. Reallocating cereal crops is the main contributor to global blue water saving with a contribution of $50 \%$ for the case of $\alpha=1.1$, followed by fruit, sugar crops and fibres with $12 \%, 10 \%$ and $9 \%$ respectively.

From a water and land perspective and aiming for global water scarcity reduction, comparative advantages for cereal production are found for the US and to a lesser extent Indonesia and France, whereas India has a comparative disadvantage. A comparative advantage exists for the US for maize, for France for wheat and barley and for Indonesia for rice. India has a comparative disadvantage in cereal production, particularly for wheat and rice. For fruit production, Brazil and the US are found to have a comparative advantage, whereas China and India have a comparative disadvantage. More specifically, the US has a comparative advan- 
tage for apples, grapes and oranges, and Ecuador and Brazil have one for bananas, while China has a comparative disadvantage for apples and India for bananas. For oil crops, Indonesia, Brazil and Argentina have a comparative advantage, and the US and Malaysia have a comparative disadvantage. Argentina and Brazil have a comparative advantage for soybean, while the US and China have a comparative disadvantage. For sugar crop production, Brazil and China are found to have a comparative advantage, while India has comparative disadvantage. Brazil and China have a comparative advantage for sugar cane, while India has a comparative disadvantage. For vegetables, we find China and India to have a comparative advantage and Turkey to have a comparative disadvantage. China has a comparative advantage for tomatoes, and Turkey has a comparative disadvantage.

By considering differences in national water and land endowments, following the Heckscher-Ohlin theory of comparative advantage, as well as differences in national water and land productivities, following Ricardo's theory of comparative advantage, we combine two rationales that are both relevant. With the optimization exercises carried out in this study, we show that blue water scarcity can be reduced to reasonable levels throughout the world by changing the global cropping pattern while maintaining current levels of global production and reducing land use. Future research could refine the current study by taking the subnational heterogeneity of water scarcity into account and by interpreting resulting changes in international trade patterns.

Data availability. The datasets generated and/or analysed during the current study are available in the Supplement and the 4TU.ResearchData repository (CC-BY-NC-ND) at https://doi.org/10.4121/uuid:64e7f59a-03f3-4e25-83c806745e9216d2 (Chouchane et al., 2020).

Supplement. The supplement related to this article is available online at: https://doi.org/10.5194/hess-24-3015-2020-supplement.

Author contributions. The three authors designed the research, analysed the data and wrote the paper. HC carried out the calculations.

Competing interests. The authors declare that they have no conflict of interest.

Acknowledgements. Hatem Chouchane and Maarten S. Krol dedicate this work to their co-author, Arjen Y. Hoekstra, who passed away unexpectedly just before the revision of this paper and whose ideas and ideals greatly influenced and will still influence a generation of scientists.
Financial support. The work by Maarten S. Krol and Arjen Y. Hoekstra was partially funded by the European Research Council (ECR) under the European Union's Horizon 2020 research and innovation programme through the project "Moving Towards Adaptive Governance in Complexity: Informing Nexus Security" (MAGIC; EU H2020 grant no. 689669) and Earth @lternatives (grant agreement no. 834716).

Review statement. This paper was edited by Gerrit H. de Rooij and reviewed by three anonymous referees.

\section{References}

Allan, J. A.: Virtual Water: A strategic resource global solutions to regional deficits, Ground Water, 36, 545-546, https://doi.org/10.1111/j.1745-6584.1998.tb02825.x, 1998.

Bouman, B. A. M.: A conceptual framework for the improvement of crop water productivity at different spatial scales, Agr. Syst., 93, 43-60, https://doi.org/10.1016/j.agsy.2006.04.004, 2007.

Brown, T. C., Mahat, V., and Ramirez, J. A.: Adaptation to Future Water Shortages in the United States Caused by Population Growth and Climate Change, Earth's Future, 7, 219-234, https://doi.org/10.1029/2018ef001091, 2019.

Chapagain, A. K., Hoekstra, A. Y., and Savenije, H. H. G.: Water saving through international trade of agricultural products, Hydrol. Earth Syst. Sci., 10, 455-468, https://doi.org/10.5194/hess10-455-2006, 2006.

Chouchane, H., Krol, M. S., and Hoekstra, A. Y.: Expected increase in staple crop imports in water-scarce countries in 2050, Water Res., 1, 100001, https://doi.org/10.1016/j.wroa.2018.09.001, 2018.

Chouchane, H., Krol, M. S., and Hoekstra, A. Y.: Dataset for: Changing global cropping patterns to minimize national blue water scarcity, Dataset, 4TU.Centre for Research Data, https://doi.org/10.4121/uuid:64e7f59a-03f3-4e2583c8-06745e9216d2, 2020.

Chukalla, A. D., Krol, M. S., and Hoekstra, A. Y.: Green and blue water footprint reduction in irrigated agriculture: effect of irrigation techniques, irrigation strategies and mulching, Hydrol. Earth Syst. Sci., 19, 4877-4891, https://doi.org/10.5194/hess-19-48772015, 2015.

Davis, K. F., Rulli, M. C., Seveso, A., and D'Odorico, P.: Increased food production and reduced water use through optimized crop distribution, Nat. Geosci., 10, 919-924, https://doi.org/10.1038/s41561-017-0004-5, 2017a.

Davis, K. F., Seveso, A., Rulli, M. C., and D'Odorico, P.: Water savings of crop redistribution in the united states, Water, 9, 83, https://doi.org/10.3390/w9020083, 2017b.

Davis, K. F., Chiarelli, D. D., Rulli, M. C., Chhatre, A., Richter, B., Singh, D., and DeFries, R.: Alternative cereals can improve water use and nutrient supply in India, Sci. Adv. 4, eaao1108, https://doi.org/10.1126/sciadv.aao1108, 2018.

Evans, R. G. and Sadler, E. J.: Methods and technologies to improve efficiency of water use, Water Resour. Res., 44, W00E04, https://doi.org/10.1029/2007WR006200, 2008. 
FAO: Review of World Water Resources by Country, Water Reports 23, Food and Agriculture Organization of the United Nations (FAO), Rome, Italy, 2003.

FAO: FAOSTAT Online Database, Statistics Division, Food and Agriculture Organization of the United Nations (FAO), Rome, Italy, 2015.

FAO: Progress on level of water stress - Global baseline for SDG 6 Indicator 6.4.2 2018, FAO/UN-Water, Rome, Italy, 2018.

Gephart, J. A., Davis, K. F., Emery, K. A., Leach, A. M., Galloway, J. N., and Pace, M. L.: The environmental cost of subsistence: Optimizing diets to minimize footprints, Sci. Total Environ., 553, 120-127, https://doi.org/10.1016/j.scitotenv.2016.02.050, 2016.

Gleick, P. H.: Global Freshwater Resources: Soft-Path Solutions for the 21st Century, Science, 302, 1524-1528, https://doi.org/10.1126/science.1089967, 2003.

Greenwood, D. J., Zhang, K., Hilton, H. W., and Thompson, A. J.: Opportunities for improving irrigation efficiency with quantitative models, soil water sensors and wireless technology, J. Agr. Sci., 148, 1-16, https://doi.org/10.1017/S0021859609990487, 2010.

Hoekstra, A. Y.: The water footprint of modern consumer society, Earthscan, Routledge, London, UK, New York, USA, xvi, 204 pp., 2013.

Hoekstra, A. Y.: Sustainable, efficient, and equitable water use: the three pillars under wise freshwater allocation, WIRES Water, 1, 31-40, https://doi.org/10.1002/wat2.1000, 2014.

Hoekstra, A. Y. and Hung, P. Q.: Globalisation of water resources: international virtual water flows in relation to crop trade, Glob. Environ. Chang., 15, 45-56, https://doi.org/10.1016/j.gloenvcha.2004.06.004, 2005.

Hoekstra, A. Y. and Mekonnen, M. M.: The water footprint of humanity, P. Natl. Acad. Sci. USA, 109, 3232-3237, https://doi.org/10.1073/pnas.1109936109, 2012.

Hoekstra, A. Y., Mekonnen, M. M., Chapagain, A. K., Mathews, R. E., and Richter, B. D.: Global monthly water scarcity: Blue water footprints versus blue water availability, PloS one, 7, e32688, https://doi.org/10.1371/journal.pone.0032688, 2012.

Jalava, M., Kummu, M., Porkka, M., Siebert, S., and Varis, O.: Diet change - a solution to reduce water use?, Environ. Res. Lett., 9, 074016, https://doi.org/10.1088/1748-9326/9/7/074016, 2014.

Jalava, M., Guillaume, J. H. A., Kummu, M., Porkka, M., Siebert, S., and Varis, O.: Diet change and food loss reduction: What is their combined impact on global water use and scarcity?, Earth's Future, 4, 62-78, https://doi.org/10.1002/2015ef000327, 2016.

Jones, H. G.: Irrigation scheduling: advantages and pitfalls of plant-based methods, J. Exp. Bot., 55, 2427-2436, https://doi.org/10.1093/jxb/erh213, 2004.

Klasen, S., Meyer, K. M., Dislich, C., Euler, M., Faust, H., Gatto, M., Hettig, E., Melati, D. N., Jaya, I. N. S., Otten, F., Pérez-Cruzado, C., Steinebach, S., Tarigan, S., and Wiegand, K.: Economic and ecological trade-offs of agricultural specialization at different spatial scales, Ecol. Econ., 122, 111-120, https://doi.org/10.1016/j.ecolecon.2016.01.001, 2016.

Konar, M., Evans, T. P., Levy, M., Scott, C. A., Troy, T. J., Vörösmarty, C. J., and Sivapalan, M.: Water resources sustainability in a globalizing world: who uses the water?, Hydrol. Process., 30, 3330-3336, https://doi.org/10.1002/hyp.10843, 2016.

Kummu, M., Guillaume, J. H. A., de Moel, H., Eisner, S., Flörke, M., Porkka, M., Siebert, S., Veldkamp, T. I. E., and Ward, P. J.:
The world's road to water scarcity: shortage and stress in the 20th century and pathways towards sustainability, Sci. Rep., 6, 38495-38495, https://doi.org/10.1038/srep38495, 2016.

Ma, T., Sun, S., Fu, G., Hall, J. W., Ni, Y., He, L., Yi, J., Zhao, N., Du, Y., Pei, T., Cheng, W., Song, C., Fang, C., and Zhou, C.: Pollution exacerbates China's water scarcity and its regional inequality, Nat. Commun., 11, 650, https://doi.org/10.1038/s41467-020-14532-5, 2020.

Mekonnen, M. M. and Hoekstra, A. Y.: The green, blue and grey water footprint of crops and derived crop products, Hydrol. Earth Syst. Sci., 15, 1577-1600, https://doi.org/10.5194/hess-15-15772011, 2011.

Mekonnen, M. M. and Hoekstra, A. Y.: Four billion people facing severe water scarcity, Sci. Adv., 2, e1500323, https://doi.org/10.1126/sciadv.1500323, 2016.

Molden, D., Oweis, T., Steduto, P., Bindraban, P., Hanjra, M. A., and Kijne, J.: Improving agricultural water productivity: Between optimism and caution, Agr. Water Manage., 97, 528-535, https://doi.org/10.1016/j.agwat.2009.03.023, 2010.

Mukherjee, A., Kundu, M., and Sarkar, S.: Role of irrigation and mulch on yield, evapotranspiration rate and water use pattern of tomato (Lycopersicon esculentum L.), Agr. Water Manage., 98, 182-189, https://doi.org/10.1016/j.agwat.2010.08.018, 2010.

Munesue, Y., Masui, T., and Fushima, T.: The effects of reducing food losses and food waste on global food insecurity, natural resources, and greenhouse gas emissions, Environ. Econ. Pol. Stud., 17, 43-77, https://doi.org/10.1007/s10018-014-0083$0,2015$.

Nouri, H., Stokvis, B., Galindo, A., Blatchford, M., and Hoekstra, A. Y.: Water scarcity alleviation through water footprint reduction in agriculture: The effect of soil mulching and drip irrigation, Sci. Total Environ., 653, 241-252, https://doi.org/10.1016/j.scitotenv.2018.10.311, 2019.

Oki, T. and Kanae, S.: Virtual water trade and world water resources, Water Sci. Technol., 49, 203-209, 2004.

Oki, T., Yano, S., and Hanasaki, N.: Economic aspects of virtual water trade, Environ. Res. Lett., 12, 044002, https://doi.org/10.1088/1748-9326/aa625f, 2017.

Osama, S., Elkholy, M., and Kansoh, R. M.: Optimization of the cropping pattern in Egypt, Alexandria Engineering Journal, 56, 557-566, https://doi.org/10.1016/j.aej.2017.04.015, 2017.

Parry, M. L., Rosenzweig, C., Iglesias, A., Livermore, M., and Fischer, G.: Effects of climate change on global food production under SRES emissions and socio-economic scenarios, Glob. Environ. Chang., 14, 53-67, 2004.

Pereira, L. S., Cordery, I., and Iacovides, I.: Improved indicators of water use performance and productivity for sustainable water conservation and saving, Agr. Water Manage., 108, 39-51, https://doi.org/10.1016/j.agwat.2011.08.022, 2012.

Sadler, E. J., Evans, R. G., Stone, K. C., and Camp, C. R.: Opportunities for conservation with precision irrigation, J. Soil Water Conserv., 60, 371-378, 2005.

Singh, R. B.: Environmental consequences of agricultural development: a case study from the Green Revolution state of Haryana, India, Agr. Ecosyst. Environ., 82, 97-103, 2000.

Vanham, D., Hoekstra, A. Y., and Bidoglio, G.: Potential water saving through changes in European diets, Environ. Int., 61, 45-56, https://doi.org/10.1016/j.envint.2013.09.011, 2013. 
Vörösmarty, C. J., Green, P., Salisbury, J., and Lammers, R. B.: Global water resources: vulnerability from climate change and population growth, Science, 289, 284-288, https://doi.org/10.1126/science.289.5477.284, 2000.

Vörösmarty, C. J., McIntyre, P. B., Gessner, M. O., Dudgeon, D., Prusevich, A., Green, P., Glidden, S., Bunn, S. E., Sullivan, C. A., Liermann, C. R., and Davies, P. M.: Global threats to human water security and river biodiversity, Nature, 467, 555-561, https://doi.org/10.1038/nature09440, 2010.

Wada, Y., van Beek, L. P. H., Viviroli, D., Dürr, H. H., Weingartner, R., and Bierkens, M. F. P.: Global monthly water stress: 2. Water demand and severity of water stress, Water Resour. Res., 47, W07518, https://doi.org/10.1029/2010WR009792, 2011.

Wada, Y., Gleeson, T., and Esnault, L.: Wedge approach to water stress, Nat. Geosci., 7, 615-617, https://doi.org/10.1038/ngeo2241, 2014.

WEF (World Economic Forum): The Global Risks Report 2019, Geneva, Switzerland, 2019.

Yang, H., Reichert, P., Abbaspour, K. C., and Zehnder, A. J.: A water resources threshold and its implications for food security, Environ. Sci. Technol., 37, 3048-3054, 2003.
Yang, H., Wang, L., Abbaspour, K. C., and Zehnder, A. J. B.: Virtual water trade: an assessment of water use efficiency in the international food trade, Hydrol. Earth Syst. Sci., 10, 443-454, https://doi.org/10.5194/hess-10-443-2006, 2006.

Ye, Q., Li, Y., Zhuo, L., Zhang, W., Xiong, W., Wang, C., and Wang, P.: Optimal allocation of physical water resources integrated with virtual water trade in water scarce regions: A case study for Beijing, China, Water Res., 129, 264-276, https://doi.org/10.1016/j.watres.2017.11.036, 2018.

Zhao, D., Hubacek, K., Feng, K., Sun, L., and Liu, J.: Explaining virtual water trade: A spatial-temporal analysis of the comparative advantage of land, labor and water in China, Water Res., 153 , 304-314, https://doi.org/10.1016/j.watres.2019.01.025, 2019.

Zhong, L., Yu, L., Li, X., Hu, L., and Gong, P.: Rapid corn and soybean mapping in US Corn Belt and neighboring areas, Sci Rep., 6, 36240, https://doi.org/10.1038/srep36240, 2016.

Zou, X., Li, Y. E., Li, K., Cremades, R., Gao, Q., Wan, Y., and Qin, X.: Greenhouse gas emissions from agricultural irrigation in China, Mitig. Adapt. Strat. Gl., 20, 295-315, https://doi.org/10.1007/s11027-013-9492-9, 2015. 